\title{
The effect of using dental and oral health book on the knowledge and skills of parents with Down Syndrome children
}

\author{
Megananda Hiranya Putri ${ }^{*}$, Hetty Anggrawati Koesoemah*, Tri Widyastuti* \\ *Department of Dental Health, Dental Nursing Study Program, Bandung Polytechnic of Health, \\ Indonesia
}

\begin{abstract}
Introduction: Down syndrome is a genetic disorder experienced by individuals due to an excess of one chromosome in the body cells as the 21 st chromosome. This trisomy 21 will result in changes in physical characteristics thus affecting the dental and oral health problems of the patient. This study was a quasiexperimental study aimed to determine the effect of using the dental and oral health book on the knowledge and skills of parents with Down Syndrome children in carrying out the children's dental and oral health care. Methods: The study design was one group pre-post test with an intervention in the form of reading a book. The sample was 36 parents of Down Syndrome children who were members of the POTADS (Persatuan Orang Tua Anak dengan Down Syndrome/Association of Parents with Down Syndrome Children) in Bandung. The statistical test used was the Wilcoxon Signed Rank Test. Results: The results showed that parents' knowledge of their Down Syndrome children's dental and oral health care and conditions were increased after reading educational books (from $(4.44 \pm 1.362)$ and $(7.47 \pm$ $2,274)$ respectively, into $(6.69 \pm 0.856)$ and $(9.00 \pm 1,394)$ respectively; $p<0.05)$. The skills of parents on performing Down Syndrome children's dental and oral health care were also increased, from (5.00 $\pm 2.014)$ into $(8.03 \pm 1.134) ; \mathrm{p}<0.05$. Conclusion: The book of Down Syndrome children's dental and oral health increased parental knowledge regarding the dental and oral health care and condition of Down Syndrome children. The book also improved the parental skills in carrying out the Down Syndrome children's dental and oral health care.
\end{abstract}

Keywords: Parental skills, book, parental knowledge, Down Syndrome, Trisomy 21

P-ISSN 1979-0201, e-ISSN 2549-6212; Available from: http://jurnal.unpad.ac.id/pjd/article/view/19277

DOI: 10.24198 /pid.vol30no3.19277

Submission: Jul 16, 2018; Accepted: Nov 14, 2018; Published online: Nov 30, 2018

Corresponding author: Megananda Hiranya Putri, Department of Dental Health, Dental Nursing Study Program, Bandung Polytechnic of Health, Indonesia. Pajajaran 56, West Java, Indonesia, 40171. Phone: +6281321057656 ; Email: mhiranyaputri@yahoo.com 


\section{INTRODUCTION}

Down syndrome is a genetic disorder known as Trisomy 21 because individuals with Down Syndrome have an extra chromosome arm. They have three arms chromosome 21 where normal people only have two. This excess chromosome will result in changes in physical characteristics and intellectual abilities, as well as disruption in the physiological functions of the body. ${ }^{1}$

The general health condition of patients with Down Syndrome will have an impact on their dental and oral health condition. Patients often experience periodontal disease, and contributing factors are poor oral hygiene, malocclusion, plaque buildup, and abnormal immune responses. Lack of patient's ability to maintain dental and oral health related to their mental limitations will worsen the condition. ${ }^{2}$

Some research results show a high prevalence of periodontal disease, and the management of these conditions in subjects with Down Syndrome is a challenge for oral health providers. ${ }^{3,4}$ Periodontitis in Down Syndrome is also associated with hypotension or muscle weakness. The weakness of this muscle tone generally affects the difficulty of carrying out manual movements skillfully, including movements to maintain personal hygiene (bathing and brushing). As a result, people with Down Syndrome usually have low levels of oral hygiene. Plaque and food retentions will accumulate, thus supporting the occurrence of gingivitis and periodontal disease. Cases of periodontitis found at an early age are a common finding in individuals with Down Syndrome and can develop rapidly. ${ }^{4}$

Children with Down Syndrome show special facial and mouth features. The middle region of the face is usually underdeveloped thus found prognathism. Patients often breathe through the mouth because the nasal passages are narrow, and the tongue is more prominent because the midface region is smaller. Hypotonus can cause the mouth to open so that salivary activity increases and the consequence is frequent angular cheilitis. The tongue is often brighter and cracked with age, and this condition can cause halitosis. ${ }^{5}$

Malocclusion is found in most Down Syndrome patients because of late tooth eruptions and the development of the maxilla. Smaller maxillaries can cause open bites, which lead to irregularities in the teeth and increased periodontal disease and dental caries. Some dental abnormalities that are often experienced by children with Down Syndrome are the absence of congenital tooth seeds, namely third molars, second incisors and premolars in the mandible.

Delay in tooth eruption is also often experienced by children with Down Syndrome. Deciduous teeth often have not erupted for up to 2 years, and have only fully grown in 4 or 5 years. Deciduous teeth sometimes continue to be in the oral cavity until children aged 14-15 years. The irregularity of the arrangement of teeth and teeth with a small size (microdontia) and teeth with deformity, also often experienced by patients with Down Syndrome. Crowns tend to be smaller, and the roots are usually small and conical, which can cause the teeth to easily detach from the supporting tissues in conditions of periodontitis. ${ }^{5,6}$

Research on the views, attitudes, and behaviour of parents about the dental health of their children with Down's Syndrome was carried out in Flanders, Belgium in 2015 against 96 subjects. The results of the study were tested with Chi-Square to see the correlation of several variables $(p<0.05)$, indicating that their views on their children's dental and oral health, in general, were rather good (53\%), $66 \%$ of children were taken to the dentist in the last 6 months, $64 \%$ of children were examined by a health worker, and parents helped Down Syndrome children when brushing their teeth (36\%), and there were 20\% of parents who had never received education to brush their teeth for their children. Conclusions from the research are the services most often performed by dentists and most needed to achieve good oral health conditions for Down Syndrome children is preventive care. ${ }^{7}$

However, there is still few research on parental knowledge about the condition and abnormalities of their Down Syndrome children oral teeth and how parents' skills help in the daily maintenance of their children's oral health. In this study, the author compiled a book on Down Syndrome which is divided into several chapters. Things discussed included understanding Down's Syndrome (understanding, type, risk factors, physical characteristics of Down Syndrome), Body System Disorders that accompany Down Syndrome 
Children, Down Syndrome Dental and Oral Conditions, Daily Maintenance of Down Syndrome Children's Oral Health and Handling Preventive Strategies in Craniofacial Abnormalities in Down Syndrome Children. This study was aimed to determine the effect of using the dental and oral health book on the knowledge and skills of parents with Down Syndrome children in carrying out the children's dental and oral health care.

\section{METHODS}

This study was a quasi-experimental study with pretest-posttest design with an intervention in the form of instructing to read a health book about Down Syndrome. The study took place from April to November 2016. April to July was used to compile a draft Dental Health Book as a guideline for parents in maintaining the dental health of children with Down Syndrome. Data retrieval was conducted from August to October 2016. The research location was in the residence of parents with Down Syndrome who are members of the POTADS Foundation (Down Syndrome Parents Association) in the city of Bandung.

This research has received Ethical approval from the Health Research Ethics Committee (KEPK) of the Bandung Polytechnic of Health with Letter Number: 13 / KEPK / PE / VIII / 2016 issued on August 8, 2016.

The study population was mothers/parents with Down Syndrome who were members of the POTADS group, namely the Parent Association of Children with Down Syndrome in Bandung totalling 97 people. The samples were mothers/ parents with Down Syndrome. The sampling method was purposive sampling with inclusion criteria: a) Mothers/parents live together in one house with Down Syndrome children, b) Mother/ parents can read and write and are willing to participate fully during the study. The exclusion criteria Mother/parents who were at the time of the study unwilling to take part and not following the overall research procedures.

The number of sample size used by respondents in this study is in accordance with the large formula of paired categorical-numerical analytical research8, namely $\mathrm{N}_{1}=\mathrm{N}_{2}=(\mathrm{Za}+\mathrm{ZB}) \mathrm{S}^{2} /$ $X_{1}-X_{2} ; Z a=$ alpha raw derivate with the value of 1.96; $Z B=$ standard beta derivative with the value of $0.84 ; \mathrm{S}=$ Standard deviation from the difference in value between groups, with the magnitude 2 times the minimum difference which considered significant; $X_{1}-X_{2}=$ minimum difference the mean considered significant with the magnitude of 20; $\mathrm{N}_{1}=\mathrm{N}_{2}=32$ people; thus the total subject was 32 people. To anticipate respondents who drop out, loss to follow up or subjects who do not comply in the research process, a number of subjects are added so that the sample size can be fulfilled, using the formula n' = N / 1 - $f$; n' = revised sample size; $\mathrm{N}=$ original sample size; $1-\mathrm{f}=$ estimated proportion of dropout, estimated at $10 \%(f=0.1)$. The sample needed for each group was n' $=32$ / $1-0.1=35.5 \sim 36$ people; thus the total number of samples was 36 people who have included the intervention group.

Independent variable was the health book about Down Syndrome with material covering daily maintenance of dental and oral health, and dental and oral conditions of Down Syndrome children; dependent variable was the knowledge and skills of parents of Down Syndrome children.

Parental knowledge is parents' knowledge about daily dental and oral health care (including: methods, the frequency and timing of proper brushing, proper toothbrush selection, use of toothpaste, and proper gargling; knowledge of the dental and oral condition often experienced people with Down Syndrome, including eruption, size, number and condition of teeth, shape and size of the tongue, palate, mouth breathing and salivary habits, condition of muscle hypotension and mouth dryness due to medications).

Parental skills are the ability of parents as a daily companion regarding dental and oral health care which includes making the right toothbrush selection, positioning the child on helping them brush their teeth, guiding brushing teeth at 7 regions and guiding mouth rinses. Parental skills were measured by observation sheets.

Every parent of Down's Syndrome children measured their initial condition in terms of their children's daily dental and oral health care knowledge and skills, then was allowed to read and study the book for 1 week, then the two variables were measured again.

The hypotheses were as follows: (1) There was a difference between parental knowledge of daily dental and oral health of children with 
Down Syndrome before and after reading health book; 2) There was a difference between parental knowledge about the dental and oral condition of the children with Down Syndrome before and after reading health book; 3) There were differences in parental skills in applying daily dental and oral health care in children with Down Syndrome before and after reading health book.

Tools and materials used in this study included: 1) Books on dental and oral health of individuals with Down Syndrome that serve as guidelines for dental and oral health care for parents with Down Syndrome children; 2) Jaw model, manual and electric toothbrushing equipment (manual toothbrush, electric toothbrush, gargle glass, toothpaste, mirror), oral physiotherapy material (gauze, antiseptic mouthwash, sprayer); 3) Informed consent sheet; 4) Questionnaire regarding cognitive abilities; 5) Observation sheet for skills assessment.
The book tested in this study was entitled: "Understanding the General Health and Dental Health of People with Down Syndrome". The book was independently developed by the author and had received IPR (Ministry of Law and Human Rights of the Republic of Indonesia) with proof of the Registration of Works No. 000123970 dated August 8, 2016.

\section{RESULTS}

The study subjects were 36 parents of Down Syndrome children (35 were mothers and 1 father) with age ranged between 32-66 years old (averagely 48 years). As much as $61.11 \%$ of the subjects were occupied, and 16 people $(50.0 \%)$ were having higher education (bachelor - doctoral degree), and 16 people (50.0\%) had secondary education (high school - diploma degree).

Table 1. Normality test results

\begin{tabular}{lrrrr}
\hline \multicolumn{1}{c}{ Variable } & Statistic $(\mathrm{D})$ & df & Sig $(\mathrm{p})$ & \multicolumn{1}{c}{ Conclusion } \\
\hline $\begin{array}{l}\text { Knowledge regarding dental and oral health care before using } \\
\text { the book's guideline }\end{array}$ & 0.214 & 36 & 0.000 & Not normally distributed \\
$\begin{array}{l}\text { Knowledge regarding dental and oral health condition before } \\
\text { using the book's guideline }\end{array}$ & 0.166 & 36 & 0.014 & Not normally distributed \\
$\begin{array}{l}\text { Skill before using the book's guideline } \\
\text { Knowledge regarding dental and oral health care after using the } \\
\text { book's guideline }\end{array}$ & 0.199 & 36 & 0.001 & Not normally distributed \\
$\begin{array}{l}\text { Knowledge regarding dental and oral health condition after using } \\
\text { the book's guideline }\end{array}$ & 0.167 & 36 & $0.000 \quad$ Not normally distributed \\
\begin{tabular}{l} 
Skill after using the book's guideline \\
\hline
\end{tabular} & 0.260 & 36 & 0.000 & Not normally distributed \\
\hline
\end{tabular}

The test results showed that the data were not normally distributed. The significance value (p) of the Kolmogorov-Smirnov test was less than 0.05 so that the different test data before and after the Wilcoxon Signed Rank Test was done.

The results of parental knowledge about the daily dental and oral health care of Down Syndrome children before and after reading the health book were indicated by the number of respondents' correct answers to each question can be seen in Table 2.

The difference test results of average scores of parental knowledge regarding daily dental and oral health care of children with Down Syndrome before and after the use of guidelines can be seen in Table 3.
The $z$-score was obtained at 5.282 with $\mathrm{p}=0.000$. $\mathrm{P}$-value $<\mathrm{a}$; which was $0.000<0.05$; thus the test results reject $\mathrm{H}_{0}$, means that there were differences in parental knowledge regarding dental and oral health care of Down Syndrome children before and after the use of health books.

The measurement results of parental knowledge about the dental and oral health condition of children with Down Syndrome before and after reading a health book about Down Syndrome were indicated by the number of correct answers of respondents on each item statement.

Average score test result of parental knowledge regarding dental and oral health condition of Down Syndrome children can be seen in Table 5. 
Table 2. Frequency distribution of parental knowledge regarding daily dental and oral health care of Down Syndrome children before and after using guideline from the book

\begin{tabular}{llcccc}
\hline No & \multicolumn{1}{c}{ Question } & $\begin{array}{c}\text { Respondent with right answer } \\
\text { before guideline }\end{array}$ & \multicolumn{2}{c}{$\begin{array}{c}\text { Respondent with right answer } \\
\text { after guideline }\end{array}$} \\
\hline & & Respondent & $\%$ & Respondent & $\%$ \\
1. & Toothbrushing method & 24 & 66.7 & 36 & 100 \\
2. & Toothbrushing frequency & 18 & 50.0 & 35 & 97.2 \\
3. $\quad$ Toothbrushing time & 8 & 22.2 & 33 & 91.7 \\
4. & The need to use toothpaste & 25 & 69.4 & 28 & 77.8 \\
5. Selecting the right toothbrush handle & 7 & 19.4 & 16 & 44.4 \\
6. Selecting the right toothbrush head & 30 & 83.3 & 35 & 97.2 \\
7. Selecting the right toothbrush bristle & 34 & 94.4 & 36 & 100 \\
8. & Proper gargling method & 14 & 38.8 & 22 & 61.1 \\
\hline
\end{tabular}

Table 3. Average score test result of parental knowledge regarding daily dental and oral health care of Down Syndrome children

\begin{tabular}{cccccc}
\hline & $\begin{array}{c}\text { Before reading } \\
\text { book }\end{array}$ & $\begin{array}{c}\text { After reading } \\
\text { book }\end{array}$ & z-score & p-value & Notes \\
\hline Mean & 4.44 & 6.69 & 5.282 & 0.000 & Significant difference \\
Standard deviation & 1.362 & 0.856 & & & \\
\hline Notes: significant in error rate of $5 \%$, if $\mathrm{p}<0.05$ & & &
\end{tabular}

Table 4. Frequency distribution of parental knowledge regarding dental and oral health condition of Down Syndrome children before and after using guideline from the book

\begin{tabular}{|c|c|c|c|c|c|}
\hline \multirow[t]{2}{*}{ No } & \multirow[t]{2}{*}{ Question } & \multicolumn{2}{|c|}{$\begin{array}{l}\text { Respondent with } \\
\text { right answer before } \\
\text { guideline }\end{array}$} & \multicolumn{2}{|c|}{$\begin{array}{l}\text { Respondent with } \\
\text { right answer after } \\
\text { guideline }\end{array}$} \\
\hline & & Respondent & $\%$ & Respondent & $\%$ \\
\hline 1. & $\begin{array}{l}\text { Teeth eruption of Down Syndrome children is the same as non-Down Syn- } \\
\text { drome children }\end{array}$ & 14 & 38.8 & 20 & 55.6 \\
\hline 2. & $\begin{array}{l}\text { Teeth size of Down Syndrome children is smaller than non-Down syndrome } \\
\text { children }\end{array}$ & 26 & 72.2 & 30 & 83.3 \\
\hline 3. & $\begin{array}{l}\text { Teeth amount of Down Syndrome children is different than non-Down } \\
\text { syndrome children }\end{array}$ & 19 & 52.8 & 27 & 75.0 \\
\hline 4. & Teeth condition of Down Syndrome children often not intact & 16 & 44.4 & 23 & 63.9 \\
\hline 5. & $\begin{array}{l}\text { Shape and size of the tongue of Down Syndrome children is different than } \\
\text { non-Down syndrome children }\end{array}$ & 22 & 61.1 & 26 & 72.2 \\
\hline 6. & $\begin{array}{l}\text { Palate of Down Syndrome children is different than non-Down syndrome } \\
\text { children }\end{array}$ & 28 & 77.8 & 29 & 80.6 \\
\hline 7. & Down Syndrome children often perform nose-breathing & 18 & 50.0 & 18 & 50.0 \\
\hline 8. & Drooling habits in Down Syndrome can cause angular cheilitis & 19 & 52.8 & 24 & 66.7 \\
\hline 9. & Hypotonic conditions make it difficult to gargle & 29 & 80.6 & 34 & 94.4 \\
\hline 10. & Routine medications can cause dry mouth & 17 & 47.2 & 27 & 75.0 \\
\hline 11 & $\begin{array}{l}\text { If Down Syndrome child often takes medications then the water consump- } \\
\text { tion needs to be increased }\end{array}$ & 29 & 80.6 & 32 & 88.9 \\
\hline 12. & $\begin{array}{l}\text { Down Syndrome children need regular checks for their dental and oral } \\
\text { condition }\end{array}$ & 32 & 88.9 & 34 & 94.4 \\
\hline
\end{tabular}


Table 5. Average score test result of parental knowledge regarding dental and oral health condition of Down Syndrome children

\begin{tabular}{|c|c|c|c|c|c|}
\hline & $\begin{array}{l}\text { Before reading } \\
\text { book }\end{array}$ & $\begin{array}{l}\text { After reading } \\
\text { book }\end{array}$ & z-score & p-value & Notes \\
\hline Mean & 7.47 & 9.00 & 4.072 & 0.000 & Significant difference \\
\hline Standard deviation & 2.274 & 1.394 & & & \\
\hline
\end{tabular}

Notes: significant in error rate of $5 \%$, if $p<0.05$

The $z$-score value was obtained at 4.072 with $p=0,000$. The $p$-value $<a$, which was 0.000 $<0.05$ thus the test results reject $\mathrm{H}_{0}$, meaning that there was a difference in parental knowledge about the dental and oral condition of Down Syndrome children before and after the use of health books.

The results of measuring parental skills in performing daily dental and oral health care in children with Down Syndrome before and after reading Down Syndrome health book were indicated by the number of respondents' correct answers to each item statement, as seen in Table 6.

Average score test result of parental skills regarding daily dental and oral health care of Down Syndrome children can be seen in Table 7.

Table 6. Frequency distribution of parental skills regarding dental and oral health care of Down Syndrome children before and after using guideline from the book

\begin{tabular}{|c|c|c|c|c|c|}
\hline \multirow[t]{2}{*}{ No } & \multirow[t]{2}{*}{ Question } & \multicolumn{2}{|c|}{$\begin{array}{l}\text { Respondent with } \\
\text { right answer before } \\
\text { guideline }\end{array}$} & \multicolumn{2}{|c|}{$\begin{array}{l}\text { Respondent with } \\
\text { right answer after } \\
\text { guideline }\end{array}$} \\
\hline & & Respondent & $\%$ & Respondent & $\%$ \\
\hline 1. & Ability to choose proper toothbrush & 19 & 52.8 & 36 & 100 \\
\hline 2. & Ability to position children when assisting to brush their teeth & 33 & 91.7 & 35 & 97.2 \\
\hline 3. & Ability to guide the proper toothbrushing technique in the left region & 7 & 19.4 & 34 & 94.4 \\
\hline 4. & Ability to guide the proper toothbrushing technique in the right region & 7 & 19.4 & 33 & 91.6 \\
\hline 5. & Ability to guide the proper toothbrushing technique in the front region & 23 & 63.9 & 36 & 100 \\
\hline 6. & $\begin{array}{l}\text { Ability to guide the proper toothbrushing technique in the maxillary } \\
\text { masticatory region }\end{array}$ & 31 & 86.1 & 34 & 94.4 \\
\hline 7. & $\begin{array}{l}\text { Ability to guide the proper toothbrushing technique in the mandibular } \\
\text { masticatory region }\end{array}$ & 33 & 91.6 & 35 & 97.2 \\
\hline 8. & $\begin{array}{l}\text { Ability to guide the proper toothbrushing technique in the inside maxillary } \\
\text { region }\end{array}$ & 2 & 5.6 & 7 & 19.4 \\
\hline 9. & $\begin{array}{l}\text { Ability to guide the proper toothbrushing technique in the inside } \\
\text { mandibular region }\end{array}$ & 7 & 19.4 & 11 & 30.6 \\
\hline 10. & Ability to guide gargling/cleanse the paste retention after toothbrush & 18 & 50.0 & 28 & 77.7 \\
\hline 11 & $\begin{array}{l}\text { If Down Syndrome child often takes medications then the water } \\
\text { consumption needs to be increased }\end{array}$ & 29 & 80.6 & 32 & 88.9 \\
\hline 12. & $\begin{array}{l}\text { Down Syndrome children need regular checks for their dental and oral } \\
\text { condition }\end{array}$ & 32 & 88.9 & 34 & 94.4 \\
\hline
\end{tabular}

Table 7. Average score test result of parental skills regarding daily dental and oral health care of Down Syndrome children

\begin{tabular}{cccccc}
\hline & $\begin{array}{c}\text { Before reading } \\
\text { book }\end{array}$ & $\begin{array}{c}\text { After reading } \\
\text { book }\end{array}$ & z-score & p-value & Notes \\
\hline Mean & 5.00 & 8.03 & 5.128 & 0.000 & Significant difference \\
Standard deviation & 2.014 & 1.134 & & & \\
\hline Notes: significant in error rate of $\mathbf{5} \%$, if $\mathrm{p}<0.05$ & & &
\end{tabular}


The $z$-score value was obtained at 5.128 with $p$-value of 0.000 . The $p$-value $<a ; p=0.000$ $<0.05$; thus the test results reject $H_{0}$, meaning that there was a difference in parental skills regarding daily dental and oral health care of Down Syndrome children before and after the use of Down Syndrome's health book.

\section{DISCUSSION}

The results of the measurement of parental knowledge regarding daily dental and oral health care of Down Syndrome children after reading the Down Syndrome Children Oral Health Book was found to be increased compared to before the intervention $(4.44 \pm 1.362)$ to $(6.69 \pm 0.856)$ at the significance level of $p<0.05$ (Table 3 ). In our study, the increase in parental knowledge was found in almost all indicators, namely how to brush teeth, the frequency of brushing teeth daily, the need to use toothpaste, how to choose toothbrush head, and the correct type of toothbrush bristle to use for children although some others' understanding did not increase (Table 2). ${ }^{9,10}$ On average, the respondents mentioned that the frequency of toothbrushing was twice a day. A small toothbrush head that can reach all parts of the child's mouth, and soft bristle that will not injure the gums, had become understood knowledge.

The item of knowledge regarding daily dental and oral health care that still had not being understood by most parents was regarding the right time to do the toothbrushing, choosing the right toothbrush handle, and how to gargle properly.

When choosing a toothbrush, most parents (81.6\%) did not care about the toothbrush handle shape and often chose curved and sometimes straight handle. Good toothbrush handle for children are straight ones, but the main principle of selecting brush handle is that they are comfortable to hold so that the children can easily brush their teeth. ${ }^{9,10}$

Regarding the correct gargling methods, most parents $(62.2 \%)$ were having a lack of understanding about how to gargle properly. Proper gargling is gargle strongly on both sides of the left and right jaws so that the mouthwash sweeps away the rest of the paste, retentions, and residual plaque due to the toothbrushing activity.
In addition to parents' lack of understanding about proper gargling, there is the fact that many Down Syndrome children experience weak facial and mastication muscles, so they are unable to gargle properly..$^{5,11,12}$

The results of the measurement of parental knowledge regarding the dental and oral health condition of Down Syndrome children was increased after reading the Down Syndrome Children Oral Health Books from $(7.47 \pm 2,274)$ to $(9.00 \pm 1,394)$; $\mathrm{p}<0.05$ (Table 5). There were several indicators regarding the dental and oral health condition of Down Syndrome children that have been understood by more than $50 \%$ of parents, even before they read the Down Syndrome Children Oral Health Book. Indicators that have been widely understood were as follows: the size and number of teeth of Down Syndrome children are not the same as non Down Syndrome children; the size of the tongue and the height of the palate in Down Syndrome children are different conditions with non Down Syndrome children; there are some habits that are often done by Down syndrome children which are drooling and mouth breathing due to the weakness of muscle tone (hypotonia).

More than $50 \%$ of parents also know that Down Syndrome children need to be encouraged to drink more water if there are regular medicines taken. Parents also recognised the condition of gingivitis/periodontitis experienced by Down Syndrome children, so parents know that routine dental examination control for their children needs to be done. After reading the book, more parents give positive answers.

Indicators that still little understood by the respondents were as follows: tooth eruption of Down Syndrome children is different from non Down Syndrome children; tooth condition of Down Syndrome children often incomplete (exfoliated enamel or quickly perforated); mouth breathing habit of Down Syndrome children especially who have a high palate; dry mouth due to regular medications.

The appearance of several indicators of the dental and oral condition of Down Syndrome children known by parents before reading the Health Book of Down Syndrome was consistent with the research conducted by Fidler ${ }^{13}$ in 2002 which included the mental retardation syndrome. The study concluded that parents of Down Syndrome 
children are more exposed to the behaviour of their children, which related to their experience than parents with Prader-Willy Syndrome and William Syndrome children. This condition was caused by the more numbers of Down Syndrome children, and the availability of health personnel and accompanying teaching staff (psychologists, teachers, speech therapists) who provided explanations more often when they enter class. ${ }^{13}$

The specific dental and oral conditions of Down Syndrome children need to be understood by parents. The lower tone of facial and mastication muscles will cause the action of cleansing plaque by the movement of the tongue, lips, and cheeks decreasing. Especially if accompanied by a dry mouth condition due to frequent consumption of medications and children with mouth breathing habit. The limited ability of children to brush their teeth due to weak muscle tone of the limbs (hands) also causes the plaque cleaning to be ineffective, resulting in plaque retention. Bacterial activity on the plaque that accumulates will potentially accelerate the formation of tooth cavity and gingival inflammation. ${ }^{11,12,14-16}$ There is a delay in the tooth eruption in Down Syndrome children, teeth with relatively smaller in size than non-Down Syndrome children, and higher palate, will cause malocclusion and masticatory function disorders (difficulty in chewing food), disruption of the child's growth and development, thus most of them will have a shorter body compared to nonDown Syndrome children. ${ }^{14-16}$

The results of our study on the parental skills in performing daily dental and oral health care of their children included choosing the proper toothbrush, positioned their children on toothbrushing, guide their children on toothbrushing in seven observation areas, and guide their children to gargle after toothbrushing, were showing improvement after reading the Health Book of Down Syndrome: $(5.00 \pm 2.014)$ to $(8.03 \pm 1.134), p<0.05$. (Table 7). Observations performed on the parents before reading the book showed that more than $50 \%$ of parents already understood how to position their children when toothbrushing, how to clear the front teeth, upper and lower masticatory region, and guide their children to gargle after toothbrush.

However, in some of these regions, most respondents brush their children's teeth with only one type of movement, which was horizontal or vertical. The results of the observation before reading the book also showed that the teeth which were less cleaned during toothbrushing were the maxillary region that faced the palate and teeth in the mandibular region which faced the tongue.

After reading the book, the average score of parental skills in performing daily dental and oral health care of Down Syndrome children was increased (Z-count $=5.128, \mathrm{p} 0.000<0.05)$. The parental skills improvement can be seen in choosing the proper toothbrush, guiding the child to clean their teeth in the front, left, right maxillary teeth, and mandibular masticatory area, and guide the child to gargle after toothbrushing. Two surfaces that were still difficult to be cleaned by the parents were the maxillary tooth surface that faces the palate and the mandibular region which faces the tongue.

Very few literatures discuss the toothbrushing technique of Down Syndrome children, limited to the toothbrushing movement expected to be done. Dental health professional recommends that proper toothbrushing frequency is at least twice a day, with a duration of 2-3 minutes, carried out with light pressure $(\leq 3 \mathrm{~N})$ with Bass technique (sweeping movements from the direction from the gums to the teeth) or it's modification. ${ }^{10}$ Research conducted by Ganss ${ }^{10}$ in 2009 of 103 adults who were asked to show their toothbrushing habit without any instructions resulted in as many as $79.6 \%$ of all subjects brushed their teeth twice a day, with an average duration of $96.6 \pm 36.6$ seconds, an average rubbing pressure of $2.3 \pm 0.7 \mathrm{~N}$, with no significant differences between quadrants; which can be concluded that only $25.5 \%$ of the subjects met the criteria. However, the study did not question the tooth region need to be cleaned.

Referring to the research result of Putri et al. ${ }^{9}$ in 2010, the principle of proper toothbrushing is to be able to clean all of the tooth surfaces, not hurting the gums, with simple, easy to learn, and systematical brushing technique, thus no region will be missed. The study suggested that specific tooth region must be cleaned. ${ }^{9}$ The condition of hypotonia in Down Syndrome children can reduce their ability to brush their teeth. In such conditions, the use of an electric toothbrush can help..$^{6,7,11}$ 
Similar research conducted by Camden et al. ${ }^{17}$ in 2016, which uses online modules to improve parental skills in supporting their children who experienced Developmental Coordination Disorder (DCD), including children with Down's Syndrome condition. $64 \%$ of the subjects after using the module, reportedly changed their skills in terms of sharing information, tried beneficial strategies, and showed changes in attitude when managing the health condition of their children with DCD. The online module proved to be able to change parental knowledge and skills significantly $(p<$ 0.01 ) from the initial score. ${ }^{17}$ The book of Down Syndrome children's dental and oral health which we created was presented enough explanation regarding the dental and oral condition of Down Syndrome children, as well as daily dental and oral health care strategy to make it understandable for the parents.

Parents with Down Syndrome children need to know the specific dental and oral conditions experienced by their child, and know how to perform daily dental and oral health care of their children. The book of Down Syndrome children's dental and oral health can become an alternative as a guide for parents and caregivers to understand and implement daily dental and oral health care for children with Down Syndrome.

\section{CONCLUSION}

The book of Down Syndrome children's dental and oral health increased parental knowledge regarding the dental and oral health care and condition of Down Syndrome children. The book also improved the parental skills in carrying out the Down Syndrome children's dental and oral health care.

\section{ACKNOWLEDGEMENT}

All authors would like to thank the manager of the POTADS Foundation (Persatuan Orang Tua Anak dengan Down Syndrome/Association of Parents with Down Syndrome Children), BPPSINDROM DOWNM (Badan Pemberdayaan dan Pengembangan Sumber Daya Manusia / Empowerment and Human Resources Development Agency), and Ministry of Health of the Republic of Indonesia for research funding.

\section{REFERENCES}

1. Desai SS. Down Syndrome: A Review of the Literature. Oral Surg Oral Med Oral Pathol Oral Radiol Endod. 1997; 84(3): 279-85. DOI: 10.1016/S1079-2104(97)90343-7

2. U.S. Department of Health and Human Services. Practical Oral Care People with Down Syndrome. National Institutes of Health National Institute of Dental and Craniofacial Research. Washington: National Institutes of Health National Institute of Dental and Craniofacial Research; 2008.

3. Cheng RH, Leung WK, Corbet EF. NonSurgical Periodontal Therapy with Adjunctive Chlorhexidine Use in Adults with Down Syndrome: A Prospective Case Series. J Periodontol. 2008; 79(2): 379-85. DOI: 10.1902/jop.2008.070247

4. van de Wiel B, van Loon M, Reuland W, Bruers J. Periodontal diseases in Down's syndrome patients. A retrospective study. Spec Care Dentist. 2018; 38(5): 299-306. DOI: $10.1111 /$ scd.12314

5. Macho V, Coelho A, Areias C, Macedo P, Andrade D. Craniofacial features and specific oral characteristics of Down Syndrome children. Oral Health Dent Manage. 2014; 13(2): 408-11.

6. Aerias CM, Sampaio B, Macho V, Norton A, Macedo AP, de Andrade DJC. Oral Health in Down Syndrome. In: Dey S. Health Problems in Down Syndrome. London: InTech Open; 2015.

7. Descamps I, Marks LA. Oral health in children with Down Syndrome: Parents' views on dental care in Flanders (Belgium). Eur J Paediatr Dent. 2015; 16(2): 143-8.

8. Dahlan MS. Besar Sampel dan Cara Pengambilan Sampel dalam Penelitian Kedokteran dan Kesehatan. $3^{\text {rd }}$ ed. Jakarta: Salemba Medika; 2013.

9. Putri MH, Herijulianti E, Nurjannah N. Ilmu Pencegahan Penyakit Jaringan Keras dan Jaringan Pendukung Gigi. Jakarta: EGC; 2010.

10. Ganss C, Schlueter N, Preiss S, Klimek J. Tooth brushing habits in uninstructed adultsfrequency, technique, duration and force. Clin Oral Investig. 2009; 13(2): 203-8. DOI: 10.1007/s00784-008-0230-8

11. Ogawa A, Ishizaki A, Asami T, Kwon H, Fujii K, Kasama K, et al. Effectiveness of Mouth Rinsing Function Test for Evaluating the Oral 
Function of Children. Pediatr Dent J. 2017; 27(2): 85-93. DOI: 10.1016/j.pdj.2017.03.002

12. Al Sarheed MA. Comparative study of oral health among Trisomi 21 children living in Riyadh, Part 2: Gingival Condition. Saudi Dent J. 2015; 27(4): 224-7. DOI: 10.1016/j. sdentj.2015.03.004

13. Fidler DJ, Hodapp RM, Dykens EM. Behavioral Phenotypes and Special Education: Parent Report of Educational Issues for Children with Down Syndrome, Prader-Willi Syndrome, and William Syndrome. J Spec Edu. 2002; 36(2): 80-8. DOI: $10.1177 / 00224669020360020301$

14. Aerias CM, Sampaio-Maia B, Guimaraes H, Melo P, Andrade D. Caries in Portuguese Children with Down Syndrome. Clinics (Sao Paulo). 2011; 66(7): 1183-6. DOI: 10.1590/ $\underline{\mathrm{S} 1807-59322011000700010}$
15. Loureiro A, Costa F, da Costa J. The impact of periodontal disease on the quality of life of individuals with Down Syndrome. Downs Syndr Res Pract. 2007; 12(1): 50-4. DOI: 10.3104/ reports.1998

16. Stefanini $M$, Sangiorgi $M$, Roncati $M$, D’Alessandro G, Piana G. Effect on plaque control in children patients with Down Syndrome using Digital Brush with or without Chlorhexidine: A randomized clinical trial. Spec Care Dentist. 2016; 36(2): 66-70. DOI: $10.1111 / \mathrm{scd} .12152$

17. Camden C, Foley V, Anaby D, Shikako-Thomas K, Gauthier-Boudreault C, Berbari J, et al. Using an evidence-based online module to improve parents' ability to support their child with Developmental Coordination Disorder. Disabil Health J. 2016; 9(3): 406-15. DOI: 10.1016/j.dhjo.2016.04.002 